\title{
Effects of Socioeconomic on Survival for Adult Glioblastoma Multiform Patients in Rio de Janeiro, Brazil, 1999-2009
}

\author{
Jose Carlos Lynch ${ }^{1}$, Leonardo Welling ${ }^{2}$, Claudia Escosteguy ${ }^{3}$, Alessandra G. L. Pereira ${ }^{3}$, \\ Ricardo Andrade ${ }^{4}$, Celestino Pereira ${ }^{4}$ \\ ${ }^{1}$ Head of Neurosurgery Department, Neurosurgery Department of Hospital dos Servidores do Estado, Rio de Janeiro, Brazil \\ ${ }^{2}$ Resident, Neurosurgery Department of Hospital dos Servidores do Estado, Rio de Janeiro, Brazil \\ ${ }^{3}$ Staff of the Epidemiology Department, Neurosurgery Department of Hospital dos Servidores do Estado, Rio de Janeiro, Brazil \\ ${ }^{4}$ Neurosurgeon, Neurosurgery Department of Hospital dos Servidores do Estado, Rio de Janeiro, Brazil \\ Email: cneuroamericas@uol.com.br
}

Received September 20, 2011; revised October 8, 2011; accepted October 30, 2011

\begin{abstract}
Backgrond: To compare the survival of glioblastoma multiforme (GBM) patients operated on at public hospital with that of patients operated on at the private hospital. Method: We carried out a retrospective analysis of the patients' medical records, the surgical reports, and the pre and post-operative images of patients with a histopathological confirmed adult supratentorial glioblastoma multiform (GBM). Sixty-three patients were treated at public hospital and 21 at private hospitals. Results: The present study revealed that the survival of patients treated in private hospitals was statistically superior to that of patients treated in public hospitals (11.9 vs 7.7). Conclusions: Our study advances towards the confirmation of the hypothesis that socioeconomic and educational factors influence the KPS and the performance of RT treatment, with negative effects over the GBM patients' survival.
\end{abstract}

Keywords: Socioeconomic Factors; Glioblastoma; Gliomas; Karnofsky; Radiotherapy

\section{Introduction}

This study aims at comparing the survival of supratentorial adult GBM patients operated on at public hospital with that of GBM patients operated on at the private hospital and observe, if besides the previously identified prognostic factors [1-7], socioeconomic factors, as previous reported by several authors, interfere in the GBM patients' survival in Brazil [8-12].

\section{Method}

We carried out a retrospective analysis of the patients' medical records, the surgical reports, and the pre and post-operative images of 66 patients with a confirmed histopathological adult supratentorial GBM diagnosis (grade 4 astrocytoma of the World Health Organization WHO) treated at public hospital or at private hospitals. The public hospital is a Ministry of Health hospital located in Rio de Janeiro, only admits patients from the Public Health System (Sistema Único de Saúde). The private hospital admit patients with either private or state corporation health insurances. The 45 public hospital patients form group number 1 . The Group 2 is formed of 21 patients operated on at the private hospitals. Consid- ering the two groups, we ended up analyzing a total of 66 patients. These patients were operated on between 1999 and 2009.

All surgeries were performed with the use of microsurgical techniques and by an experienced group of neurosurgeons (JCL, RA, CP) who were responsible for all surgeries in both groups of patients. In the series from the public hospital the chief resident operated on some patients but always under direct supervision from one of the above-mentioned neurosurgeons. Both hospitals have well equipped operative suites with neurosurgical microscopes, bipolar, ultrasound aspirators, and microsurgical instruments. Regardless of the group, we use the same general principles when proceeding with tumor resection. The surgical philosophy followed for these tumors was to obtain a complete microsurgical tumor resection, particularly in patients who are relatively young. Therefore, in regard to the microsurgical techniques we obtain a quite homogeneous surgical philosophy, decreasing possible selection biases. Our attention was drawn to the acquisition of data referring to age, pre-surgery neurological condition, measures based on the KPS scale, tumor resection extent and performance of radiotherapy (RT). We carried out an investigation to find out whether 
socioeconomic and educational factors interfered in the patients' survival. To test the difference within the distribution continuous variables, the Mann-Whitney test was utilized; for the difference between proportions, the chi-square test (or the Fisher test, if needed) was used. Kaplan-Meier's methods were used for survival estimate, and the Cox method for proportional hazard ratio estimate, using Epi Info 3.4 software.

\section{Results}

\subsection{Survival}

Surgical death (until 30 days after surgery) occurred with $3(6.7 \%)$ patients operated on at a public hospital and with one $(4.8 \%)$ individual operated on at private hospitals. The average survival rate of the whole group, taking into consideration the period starting from the moment of the surgery up to the last evaluation or death was of 9.3 months. For group 1 the average survival rate was of 7.7 \pm 8.9 months and for group 2 of $11.9 \pm 7.0$ months $(\mathrm{p}=$ $0.01)$. The comparison of survival probability between the 2 groups based on the Kaplan-Meier method suggested a superior survival rate among the patients operated on at private hospitals (group 2), a statistically significative finding $(\mathrm{p}=0,005)$. A 6-month survival probability estimate happened in $89 \%$ of the private hospital patients vs $63 \%$ in the public one; a 12 -month estimate happened in $70 \%$ vs $24 \%$ of the patients respectively, and an 18 -month in $33 \%$ vs $5 \%$ (Figure 1 ).

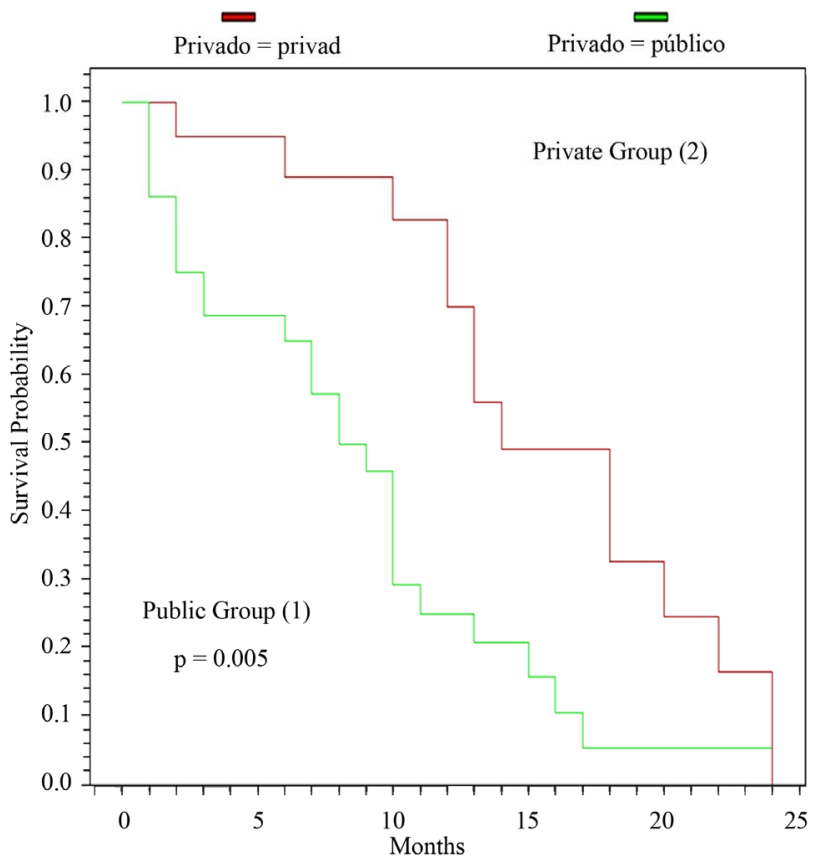

Figure 1. Accumulated survival probability based on patients with glioblastoma multiforme operated on in public or private hospitals (Kaplan-Meier method).

\subsection{Prognostic Factors}

Age and Sex-Our population consisted of 31 women $(47 \%)$ and 35 men $(53 \%)$. The age varied from 27 to 84 (average of 55). The sex and age distribution did not present a statistically significative difference between the two groups, although the percentage of individuals with 50 years of age or above was higher in group 1.

Tumor resection extent-In group 1, total removal was performed in $22(48.9 \%)$ of the cases. In group 2, total removal was performed in 15 instances (71.4\%).

Patients reoperation was performed in 2 patients, in the group 2 and in 3 instances in the group 1. The individuals with total removal had a superior survival, if compared with that of those that have undergone a partial one, but with no statistical significance $(\mathrm{p}=0.057)$.

Karnosfsky - In group 1, the median was of 70 with extremes between 50 and 100, KPS superior to 70 only among $24(53.3 \%)$ of the patients. In group 2 an average KPS of 90 was found, varying from 70 to 100; all the individuals in this group presented KPS superior to 70 . Group 2, KPS was significatively superior to that of group 1. In our study, the individuals with KPS inferior to 70 had a shorter survival when compared to those with KPS superior to 70 . This finding was statistically significative $(\mathrm{p}=0.001)$.

Radiotherapy-In group 1, only 27 (60\%) patients completed the prescribed RT. However, in group 2, 17 $(84 \%)$ individuals concluded the treatment. The patients who finished radiotherapy had a superior survival. This finding was statistically significative $(p<0.0001)$. During the period of this study, temozolamide were not available for use in the public hospital, therefore we do not include this topic in our analyze.

\subsection{Multivariate Analysis: Adjusted Survival}

A heterogeneous distribution of some prognostic factors between the two groups, such as KPS and the use of RT could justify the smaller survival in group 1 (public). Table 3 shows the death hazard for the group public versus private, gross and adjusted to some variables, using Cox proportional hazards model. It was observed that the gross death proportional hazard was 2.59 times superior in the public group when compared to the private one (model 1) (Tables 1-3).

\section{Discussion}

GBM is the most frequent brain tumor among adult patients [1-7].

The present survival rate of a patient with GBM is approximately of one year and only occasionally; some individuals may reach a superior survival rate $[13,14]$.

Surgery and RT are still considered the basic treatment, and can be complemented with chemotherapy $[1-4,6,13$, 15-20]. 
Table 1. Distribution of some continuous variables based on the public groups (1) and private groups (2) of patients with glioblastoma multiforme.

\begin{tabular}{lccc}
\hline \multirow{2}{*}{ Variable } & Public & Private & \\
\cline { 2 - 4 } & Average \pm standard-deviation & Average \pm standard-deviation & $\mathrm{p}$ (Mann-Whitney) \\
\hline Age (years) & $56.0 \pm 13.1$ & $55.2 \pm 14.7$ & 0.6297 \\
Average distance to the place of treatment (Km) & $23.7 \pm 13.8$ & $14.6 \pm 16.4$ & 0.0085 \\
Duration of symptoms until diagnosis (months) & $2.76 \pm 2.26$ & $1.67 \pm 1.02$ & 0.0959 \\
KPS & $70.0 \pm 12.97$ & $87.1 \pm 7.8$ & 0.0000 \\
Follow-up (months) & $7.44 \pm 8.9$ & $11.95 \pm 7.0$ & 0.0060 \\
\hline
\end{tabular}

Table 2. Cox proportional hazard model of death within one year in patients with glioblastoma multiforme operated on in a public hospital versus in a private hospital.

\begin{tabular}{|c|c|c|c|c|c|}
\hline & \multicolumn{2}{|c|}{ Public } & \multicolumn{2}{|c|}{ Private } & \multirow[t]{2}{*}{$\mathrm{p}\left(\chi^{2}\right.$ or Fisher $)$} \\
\hline & $f$ & $\%$ & $\mathrm{~F}$ & $\%$ & \\
\hline Sex & & & & & 0.3237 \\
\hline Femele & 23 & $51.1 \%$ & 8 & $38.1 \%$ & \\
\hline Male & 22 & $48.9 \%$ & 13 & $61.9 \%$ & \\
\hline AGE & & & & & 0.3509 \\
\hline$\geq 50$ years & 31 & $68.9 \%$ & 12 & $57.1 \%$ & \\
\hline$<50$ years & 14 & $31.1 \%$ & 9 & $42.9 \%$ & \\
\hline KPS & & & & & 0.0004 \\
\hline$\geq 70$ & 24 & $53.3 \%$ & 21 & $100.0 \%$ & \\
\hline Until 60 & 21 & $46.7 \%$ & 0 & $0.0 \%$ & \\
\hline Surgical Death & & & & & 0.8012 \\
\hline Yes & 3 & $6.7 \%$ & 1 & $4.8 \%$ & \\
\hline No & 42 & $93.3 \%$ & 20 & $95.2 \%$ & \\
\hline Radiotherapy & & & & & 0.0019 \\
\hline RT & 27 & $60.0 \%$ & 18 & $85.7 \%$ & \\
\hline No & 18 & $40.0 \%$ & 3 & $14.3 \%$ & \\
\hline Treatment & & & & & 0.1198 \\
\hline Total & 23 & $51.1 \%$ & 15 & $71.4 \%$ & \\
\hline Subtotal & 22 & $48.9 \%$ & 6 & $28.6 \%$ & \\
\hline
\end{tabular}

Table 3. Hazard ratio. Public versus private.

\begin{tabular}{lccc}
\hline \multicolumn{1}{c}{ Term } & Hazard Ratio (HR) & IC 95\% & p-value \\
\hline Model 1 & & & \\
Public vs private & $2.59^{1}$ & $1.29-5.18$ & 0.007 \\
Model 2 & & & \\
Public vs private & $1.54^{2}$ & $0.67-3.56$ & 0.313 \\
Age (continuous) & 1.03 & $1.00-1.06$ & 0.043 \\
KPS $<70$ vs KPS $\geq 70$ & 2.84 & $1.21-6.65$ & 0.016 \\
RT yes vs no & 0.19 & $0.07-0.54$ & 0.002 \\
\hline
\end{tabular}

The present investigation revealed that survival time of patients from group 2 (11.9 months) was statistically superior to that of patients from group 1 (7.4 months). We also observed that prognostic factors such as KPS and RT performance were worse within patients treated in public hospitals, which may probably partially explain the difference of survival rates between the two groups. This study is limited by drawbacks of a retrospective analysis and the relative low numbers of patients. Only a large prospective study can overcome this weakness.

The Human Development Index (HDI) is a composite statistical measure used by the United Nations (UN) to rank countries according to the level of "human development" and separate high development, middle development, and low development countries. The statistics is composed from data on expectancy life, education and per-capita GPS as an indicator of standard of living, collected at the national or local level. We detected that the average HDI of the public patients varied from 0.798 0.711 (low development) but in the private group the average IDH varied from 0.970 - 0.938 (high development).

The average time between the appearance of the first symptoms and surgery was of $1.67+/-1.02$ months for group 2 and of $2.76+/-2.26$ months for patients treated in public hospital.

The group 1 did worse, they had a more advanced disease, maybe due to lack of knowledge when or where to seek medical care, which means it takes lot of time to the initial diagnosis and also the long awaiting list to realize the prescribed surgery, so less like to get macroscopic total tumor resection and also more co-morbity leading to lower Karnosfsky at presentation, interfering in survival.

Twenty-seven patients (40\%) in group 1 did not finish $\mathrm{RT}$, contrasting with the private group where only 3 patients (14\%) did not finish the RT. In group 1, 17 (82\%) patients live in the city outskirts. The average distance between their houses and the place where RT is done is $23.7+/-13.8 \mathrm{~km}$. In the private group, the average distance between their houses and the place where RT is done is $14.6+/-16.4 \mathrm{~km}$. The discrepancy found between 
the two groups may be partially explained because of the long distance between the patients' place of residence and the place where RT is performed. Another possible explanation for these disparities was the patient's deterioration and he or she was no longer felt suitable to continue the treatment. After analyzing these data, we decided to hold the discharge in group 1, until these patients finished the prescribed RT. This is a prognostic factor, which probably had a negative impact on the worse survival rate found in group 1.

Jagger C et al. [8] found that, in Europe, there is a decrease in life expectation within less socially privileged groups. They claim that the significant difference in health quality found among the European Community countries represent manifestations of unfavorable environmental, social and economic factors.

Inskip PD et al. [11] observe that, in the United States, education and family influence brain tumor diagnosis. They assert that people with no health insurance or with a governmental insurance (Medcaid) have a later brain tumor diagnosis. The delay of medical treatment, access to specialists and to imaging studies lead to late diagnosis. While early diagnosis allows for a more effective treatment, any delay in the diagnosis and in the beginning of the treatment is, on the other hand, extremely important for the patients 'survival. Recently, Curry et al. [21] report racial, ethnic and social disparities in patient's outcome after craniotomy for tumor in the United States. In this paper, they examined the sort-term patients' outcomes that underwent craniotomies for brain tumor and found consistent evidence of poorer short-term outcomes for members of certain socially disadvantaged groups, which typically contain persons who are uninsured and lack access to primary care physicians and expensive imaging tests. They concluded that both race and socioeconomic status have been shown to be an important predictor of outcome after complex surgical procedures in the US.

We may conclude that the present study revealed that the non-adjusted survival of patients in group 2 (private) was statistically superior to that of patients in group 1(public), average survival of 11.9 months vs 7.7 . The patients from group 1 have a low level of education and low family income. The prognostic factors such as KPS and RT performance were statistically worse among these patients.

Our study moves towards proving the hypothesis that besides medical factors, socioeconomic and educational factors may contribute to a have negative influence over the survival. This disparity can be alleviating with a better education, establishing health clinics in poor areas of the city, access to specialists and to imaging studies. While early diagnosis allows for a more effective treatment, any delay in the diagnosis, on the other hand, is extremely important for the patients 'survival.

Declaration of interest: The authors report no conflicts of interest. The authors alone are responsible for the content and writing of the paper.

\section{REFERENCES}

[1] M. Lacroix, D. Abi-Said, R. Fourney, Z. L. Gokaslan, W. Shi, F. DeMont, F. F. Lang and E. McCutcheon, "A Multivariate Analysis of 416 Patients with Glioblastoma Multiforme: Prognosis, Extent of Resection, and Survival," Journal of Neurosurgery, Vol. 95, No. 2, 2001, pp. 190198. doi:10.3171/jns.2001.95.2.0190

[2] G. E. Keles, B. Anderson and M. S. Berger, "The Effect of Extent of Resection on Time to Tumor Progression and Survival in Patients with Glioblastoma Multiforme of the Cerebral Hemisphere," Surgery Neurology, Vol. 52, No. 4, 1999, pp. 371-379. doi:10.1016/S0090-3019(99)00103-2

[3] W. Stummer, H. Reulen, T. Meinel, U. Pichlmeier, W. Schumacher and J. Tonn, "Extent Resection and Survival in Glioblastoma Multiforme: Identification of and Adjustment for Bias," Neurosurgery, Vol. 62, 2008, pp. 564576. doi:10.1227/01.neu.0000317304.31579.17

[4] J. R. Simpson, J. Horton, C. Scott, W. J. Curran, P. Rubin and J. Fischbach, "Influence of Location and Extent of Surgical Resection on Survival of Patients with Glioblastoma Multiforme: Results of Three Consecutive Radiation Therapy Oncology Group (RTOG) Clinical Trials," International Journal of Radiation Oncology Biology Physics, Vol. 2, 1993, pp. 239-244. doi:10.1016/0360-3016(93)90203-8

[5] P. Yuile, O. Dent, R. Cook, M. Biggs and N. Little, "Survival of Glioblastoma Patients Related to Presenting Symptoms, Brain Site and Treatment Variables," Journal of Clinical Neuroscience, Vol. 13, No. 7, 2006, pp. 747751. doi:10.1016/j.jocn.2005.10.011

[6] C. R. Miller and A. Perry, "Glioblastoma Morphologic and Molecular Genetic Diversity," Arch Pathology Laboratory Medicine, Vol. 131, No. 3, 2007, pp. 397-406.

[7] J. F. Mineo, A. Bordron, M. Baroncini, C. Ramirez, C. A. Maurage, S. Blond and P. Dam-Hieu, "Prognosis Factors of Survival Time in Patients with Glioblastoma Multiforme: A Multivariate Analysis of 340 Patients," Acta Neurochirurgica, Vol. 149, 2007, pp. 245-253.

doi:10.1007/s00701-006-1092-y

[8] C. Jagger, C. Gillies, F. Moscone, E. Cambois, H. Van Oyen, W. Nusselder and J. Robine, "Inequalities in Healthy Life Years in the 25 Countries of the European Union in 2005: A Cross-National Meta-Regression Analysis," The Lancet, Vol. 372, No. 9656, 2008, pp. 21242131. doi:10.1016/S0140-6736(08)61594-9

[9] M. Wrensch, T. Rice, R. Miike, A. McMillan, K. R. Lamborn, K. Aldape and M. D. Prados, "Diagnostic, Treatment, and Demographic Factors Influencing Survival in a Population-Based Study of Adult Glioma Patients in the San Francisco Bay Area," Neuron-Oncology, Vol. 26, No. 4, 2006, pp. 12-26. doi: $10.1215 / \mathrm{S} 1522851705000268$ 
[10] S. M. Chang and F. G. Barker II, "Marital Status, Treatment and Survival in Patients with Glioblastoma-Multiforme: A Population-Based Study," Cancer, Vol. 104, 2005, pp. 1975-1984. doi:10.1002/cncr.21399

[11] P. D. Inskip, R. E. Tarone, E. E. Hatch, T. C. Wilcosky, H. A. Fine, P. M. Black, J. S. Loeffler, W. R. Shapiro, R. G. Selker and M. S. Linet, "Sociodemographic Indicators and Risk of Brain Tumors," International Journal of Epidemiology, Vol. 32, No. 2, 2003, pp. 225-233. doi:10.1093/ije/dyg051

[12] P. Salander, A. T. Bergenheim, K. Hamberg, R. Henriksson, "Pathways from Symptoms to Medical Care: A Descriptive Study of Symptom Development and Obstacles to Early Diagnosis in Brain Tumors Patients," Family Practice, Vol. 16, No. 2, 1999, pp. 143-148. doi:10.1093/fampra/16.2.143

[13] R. Stupp, W. P. Mason, M. J. Bent, M. Weller, M. J. B. Taphoorn and K. Belanger, "Radiotherapy plus Concomitant and Adjuvant Temozolomide for Glioblastoma," New England Journal of Medicine, Vol. 352, 2005, pp. 987-996. doi:10.1056/NEJMoa043330

[14] F. T. Vertosick Jr, R. G. Selker, I. F. Pollack and V. Arena, "The Treatment of Intracranial Malignant Gliomas Using Orally Administered Tamoxifen Therapy: Preliminary Results in a Series of "Faleid" Patients," Neurosurgery, Vol. 30, 1992, pp. 897-903. doi:10.1227/00006123-199206000-00014
[15] C. J. Wheeler, J. S. Yu and K. L. Black, "Cellular Immunity in the Treatment of Brain Tumors," Clinical Neurosurgery, Vol. 51, No. 3, 2004, pp. 132-139.

[16] S. Puget and J. T. Rutka, "Malignant Brain Tumors: Two Steps Forward," Clinical Neurosurgery, Vol. 54, 2007, pp. 4-9.

[17] J. W. Henson, "Treatment of Glioblastoma Multiforme," Arch Neurology, Vol. 63, No. 3, 2006, pp. 337-341. doi:10.1001/archneur.63.3.337

[18] M. Salcman, H. Scholtz, R. S. Kaplan and S. Kulik, "Long-Term Survival in Patients with Malignant Astrocytoma," Neurosurgery, Vol. 34, No. 2, 1994, pp. 213219. doi:10.1227/00006123-199402000-00002

[19] K. L. Chandler, M. D. Prados, M. B. A. Malec and C. B. Wilson, "Long-Term Survival in Patients with Glioblastoma Multiforme," Neurosurgery, Vol. 32, 1993, pp. 716720. doi:10.1227/00006123-199305000-00003

[20] D. Krex, B. Klink, C. Hartmann, A. Von Deimling, T. Pietsch, M. Simon and M. Sabel, "Long-Term Survival with Glioblastoma Multiforme," Brain, Vol. 130, No. 10, 2007, pp. 2596-2606. doi:10.1093/brain/awm204

[21] W. T. Curry Jr., B. S. Carter and F. G. Barker, "Racial, Ethic, and Socioeconomic Disparities in Patient Outcome after Craniotomy for Tumor in Adult Patient in the United State, 1988-2004," Neurosurgery, Vol. 66, No. 3, 2010, pp. 427-438. doi:10.1227/01.NEU.0000365265.10141.8E 